\title{
CARLOS AUGUSTO DE FIGUEIREDO MONTEIRO, O GEÓgRAFO
}

\author{
José Bueno Conti*
}

\begin{abstract}
RESUMO:
O artigo passa em revista a obra científica do Prof. Carlos Augusto de Figueiredo Monteiro, enfatizando suas inovações de caráter metodológico. Destaca alguns de seus trabalhos mais importantes e assinala, ainda, sua contribuição no campo das relações entre Climatologia e Filosofia e Geografia e Literatura.
\end{abstract}

\section{PALAVRAS-CHAVE:}

geossistema, análise rítmica, semi-árido, clima urbano.

\section{ABSTRACT:}

The article passes in a magazine the scientific work of the Prof. August Carlos de Figueiredo Monteiro, emphasizing his innovations of methodologic character. He detaches some of his most important works. He designates his contribution in the field of the relations between Climatology and Philosophy and Geograpahy and Literature as well.

\section{KEY WORDS:}

geossystem, rhythmic analysis, half-barren, urban climate.

"Neste ano de 2007 celebrarei o meu $80^{\circ}$ aniversário. Tem sido uma longa travessia enfrentando a MÁQUINA DO MUNDO a partir da estrada pedregosa do Piauí". Foi esta frase que Carlos Augusto de Figueiredo Monteiro, inspirado num verso de Carlos Drumond de Andrade, colocou em seu cartão de Natal de 2006, muito bem ilustrado com um desenho, à bico de pena, mostrando a cidade colonial de Outro Preto, em todo seu esplendor barroco.

Em julho de 1962, às margens do São Francisco, conheci, pessoalmente, Carlos Augusto, embora já tivesse lido vários de seus textos nos meus tempos de aluno da Faculdade de Filosofia da USP. Foi uma glória ver, em carne e osso, aquele professor já renomado, embora tivesse apenas 35 anos. Estávamos todos participando da XVII Assembléia Geral da Associação dos Geógrafos Brasileiros (AGB) em Penedo, Alagoas e eu encantado em conhecer o Nordeste. Já havia tomado parte em três Assembléias Gerais da AGB, em Colatina (ES) em 1957, Santa Maria (RS) em 1958 e Londrina (PR) em 1961, mas aquela era a primeira que me levava ao norte do país. Queria conhecer o semi-árido, região do Brasil que desde minha infância me fascinou por sua natureza agreste e sua corajosa população. Lá fiquei sabendo que Carlos Augusto era nascido em Teresina, a bela capital do Piauí, que eu só iria ter o prazer de conhecer, em 1978. 
Naquela reunião ele produziu um trabalho que se tornaria antológico: Aspectos Geográficos do Baixo São Francisco (Avulso $\mathrm{n} \cong$ 5, editado pela $A G B$, São Paulo, 1962), resultado do trabalho de uma equipe integrada, entre outros, por Caio Prado Jr., Dora de Amarante Romariz, Maria da Conceição Vicente de Carvalho, Orlando Valverde, Teresa Cardoso da Silva, Lea Goldenstein, Gil Sodero de Toledo, Olga Cruz e Pedro Dal Rio. Entre os dias 8 e 11 de julho de 1962, esses estudiosos fizeram um minucioso trabalho de campo, investigando os aspectos da natureza e da sociedade e todas as suas complexas interações na foz do grande rio, especialmente as características naturais e a estrutura dos fatos agrários. O relatório final, além de muito bem ilustrado com gráficos, tabelas e fotografias, apresentou uma inovação metodológica, uma vez que a área pesquisada foi apresentada no formado de um geossistema. Tratava-se de proposta inédita, entre nós, até então só praticada pelos geógrafos soviéticos (Sotchava) e depois pelos franceses (Bertrand), que preconizava o estudo integrado da realidade geográfica, levando em conta o potencial ecológico, a exploração biológica e a ação antrópica, conduzindo a construção de uma síntese que seria o geossistema. Esse relatório tornar-se-ia um modelo para inúmeros trabalhos posteriores, em todo o Brasil, especialmente entre os estudos geografia da natureza.

Anos depois, quando esse novo paradigma já era de uso corrente, o Prof. Monteiro escreveria um livro no qual resgatou esse trabalho realizado no Baixo São Francisco: Geossistemas, a história de uma procura, editado pela Contexto (São Paulo, 2000), em que narra a trajetória da metodologia geossistêmica, desde o seu surgimento na década sessenta. É interessante transcrever alguns trechos:

Por mais rápida ou superficial que houvesse sido o nosso reconhecimento da área, não restava dúvidas sobre seu caráter peculiar. Dificilmente se encontraria um espaço territorial onde as riquezas de interação dos fatos naturais propiciasse recursos e estes fossem aproveitados tão engenhosamente pela população, quanto aquela da várzeas arrozeiras do Baixo São Francisco. E, em contrapartida, um baixo nível de vida que traduzia toda a responsabilidade de uma cruel estruturação social. Tal riqueza de interações jamais poderia ser apresentada segundo um raciocínio linear, exibido em seqüência dos diferentes tópicos. Assim sendo, procurei juntar a documentação recebida dos colegas às minhas próprias observações despendendo toda a noite subtraída ao sono, na montagem de um esquema representativo do conjunto considerado e suas unidades" (pág. 15).

Nasceu assim o ESQUEMA GERAL DAS RELAÇÕES ENTRE O QUADRO NATURAL E A OCUPAÇÃO HUMANA, publicado, originalmente, à pág. 22 do Avulso no 5, anteriormente citado, onde as quatro "unidades morfoestruturais" (várzeas, vertentes das várzeas, tabuleiros, e feições litorâneas) são caracterizadas com os correspondentes "tipos efetivos de ocupação humana". Ou seja, ali figurava de maneira clara a noção integradora da proposta geossitêmica, envolvendo potencial ecológico, exploração biológica e ação antrópica.

Em 1978 o Prof. Monteiro havia apresentado uma comunicação em um simpósio promovido pela Secretaria de Ciência e Tecnologia e Academia de Ciências do Estado de Paulo, sob o título Derivações antropogênicas dos geossistemas terrestre no Brasil e alterações climáticas no qual enfatizava a "concepção teórica do geossitema como veículo integrador da abordagem geográfica".

Oriundo de um estado nordestino assolado pela semi-aridez, o piauiense Carlos Augusto dedicou várias de suas pesquisas a essa vasta área do território brasileiro que, de longa data, vinha sendo objeto de atenção dos estudiosos, inclusive de Euclides da Cunha, com sua magistral obra Os Sertões.

Um dos mais destacados trabalhos do 
Prof. Carlos Augusto, nessa temática, foi publicado no Japão, na Universidade de Tsukuba, em 1988, instituição onde esteve de 1982 a 1983 como pesquisador visitante estrangeiro no "Projeto Espacial de Pesquisa sobre a América Latina". Nesse "paper", intitulado On the "desertification" in Northeast Brazil and man's rule on this process (Latin American Studies no 9), analisa a região confrontante dos estados do Ceará, Paraíba, e Pernambuco, sendo o foco principal da investigação, a relação homem/natureza e as conseqüências desse processo interativo para o agravamento do processo de desertificação. O texto foi elaborado de forma original em que o autor cria personagens (os "Severinos" 1, 2 e 3) e, narrando as trajetórias de cada um, expõe a dureza da vida do sertanejo e sua luta desigual contra a seca e a estrutura "coronelista" ali vigente desde o século XVI. No plano teórico, retoma a discussão do conceito de geossistema reafirmando que

“são organizações geográfico-espaciais onde os aspectos sócio-econômicos não devem ser sobrepostos aos geo-ecológicos. Se os primeiros têm peso suficiente, podem ser incluídos como um fator determinante no início do estudo ou na definição das "unidades espaciais" (...) O entendimento profundo da organização espacial deve incluir todos os processos dinâmicos no tempo - naturais e sociais - que são essencialmente importantes".

Caracteriza, ao longo do texto, os vários geossistemas que compõem a região, nos quais os geótopos "altos pelados" e as malhadas" seriam os habitats, por excelência, dos Severinos, estabelecendo, ainda, um paralelo entre o sertão nordestino, e o Sahel Africano, especialmente em seus aspectos demográficos e econômicos. A frase de encerramento merece ser reproduzida: "Os sertões estão em toda parte. Inclusive dentro de nós mesmos. Devemos tomar seriamente esta mensagem, a menos que queiramos desertificar nossas entranhas".

No campo específico da Climatologia, também foi um precursor, bastando lembrar o paradigma da análise rítmica lançado por ele, em 1971, que obteve enorme aceitação entre a comunidade estudiosa. Até o ano 2000 já haviam sido produzidos, só em nosso país, 180 trabalhos acadêmicos inspirados nessa metodologia, como demonstra o Prof. João Afonso Zavatini em seu livro Estudos do clima no Brasil, publicado em 2004 pela Editora Alínea, de Campinas (SP).

No plano da contribuição metodológica um de seus mais notáveis trabalhos foi Teoria e Clima Urbano, editado pelo Instituto de Geografia da USP em 1976, brilhante ensaio teórico e uma reflexão riquíssima sobre a questão dos paradigmas, estabelecendo um paralelo entre as propostas de Sorre e de Hann, passando por Pédélaborde e outros, delineando, assim, a evolução da linha de pesquisa climatológica em sintonia com as mudanças operadas no conjunto da ciência geográfica.

O capítulo dedicado ao clima urbano, enfatiza o que chama de "inferências", destacando quatro: a despreocupação com o estudo do ambiente natural no campo da Geografia Urbana, a preponderância da Teoria Geral dos Sistemas, a ênfase na análise da estrutura urbana e, finalmente, o resgate do interesse pelo ambiente natural e seus aspectos qualitativos, considerados como "novos recursos". O capítulo se encerra com uma discussão sobre o conflito metodológico da Geografia na época, e o apelo ao estudo da filosofia da ciência para resolver a crise.

Antes das Considerações Finais, propõe um quadro de referência teórica para o estudo do clima urbano tomado este como um "sistema dinâmico adaptativo".

Evidentemente, esta brevíssima resenha está longe de mostrar toda a enorme dimensão da obra, ainda hoje, referência para os estudos de clima urbano não só para os geógrafos, mas para os arquitetos, urbanistas, engenheiros e ambientalistas. Em 2006, o VII Simpósio Brasileiro de Climatologia Geográfica realizado 
em Rondonópolis (MT) prestou justa homenagem pelo transcurso do trigésimo aniversário de sua publicação, sendo o autor, presente ao evento, reverenciado pela comunidade climatológica brasileira ali reunida.

A obra do Prof. Monteiro passa, também, pela filosofia e, nessa linha, mencionaríamos o livro Clima e Excepcionalismo, de 1971, publicado pela Universidade Federal de Santa Catarina, que teve grande repercussão no meio culto pois, além de ser um balanço crítico sobre o que, até então havia feito, apresentou um interessante cotejo entre Climatologia e Filosofia.

Nos últimos anos o Prof. Monteiro vem se consagrando ao tema Geografia e Literatura, hoje uma das mais importantes linhas de pesquisa no contexto da Geografia Humanística. O livro o mapa e a trama. Ensaio sobre ao conteúdo geográfico em criações romanescas, também publicado pela Universidade Federal de Santa Catarina, em 2002, analisa em profundidade as obras da literatura nacional que trazem matéria de interesse geográfico, focalizando Aluísio de Azevedo, Lima Barreto e Machado de Assis, autores que produziram algumas das obras primas de nossa literatura como 0 cortiço, Triste fim de Policarpo Quaresma e Memórias Póstumas de Brás Cubas. Passa, em seguida, aos regionalistas dando relevo a Graciliano Ramos e seu excelente romance Vidas Secas e, ainda, a Graça Aranha, com Canaã. Destaca, de maneira especial, a obra de João Guimarães Rosa, notadamente seus romances Corpo de Baile e

\section{Grande Sertão: veredas.}

Nas conclusões do livro, que é muitíssimo mais denso do que esta breve referência que aqui faço, afirma que a criação literária não substitui a Geografia, mas é uma complementação enormemente enriquecedora.

Haveria muito mais a acrescentar sobre a produção geográfica do Prof. Carlos Augusto de Figueiredo Monteiro, sendo digno de se ressaltar que, mesmo quando se dedicava prioritariamente aos estudos da atmosfera, não gostava de ser chamado de climatólogo, preferindo ser reconhecido como geógrafo. Como professor e pesquisador nunca perdeu de vista a singularidade de nossa ciência e sempre transmitiu aos seus alunos esse importante ensinamento. Eu fui um deles e também segui seus passos, passando a defender a mesma tese ao longo de minha trajetória docente.

A obra que o Prof. Monteiro até aqui já realizou é imensa. São dezenas de artigos, livros, ensaios, relatórios técnicos, etc., os quais, acima de tudo, oferecem uma contribuição excepcionalmente importante para as reflexões sobre a natureza e seu papel enquanto suporte da ação transformadora da sociedade.

O Departamento de Geografia, da Faculdade de Filosofia, Letras e Ciências Humanas da USP, orgulha-se de ter tido o Prof. Carlos Augusto de Figueiredo Monteiro entre seus quadros durante duas décadas (19681987). 
